\title{
An Update on the Endoscopic Management of Food Bolus Obstruction (FBO)
}

ISSN: 2637-7632

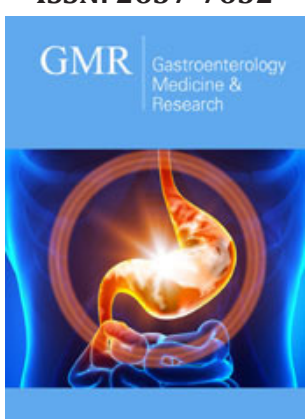

*Corresponding author: Nam Nguyen, Professor, Department of Gastroenterology and Hepatology, Australia

Submission: 价 December 02, 2019

Published: 漈January 22, 2020

Volume 4 - Issue 2

How to cite this article: Marie 0 , Tuan A D, Nam Q N. An Update on the Endoscopic Management of Food Bolus Obstruction (FBO). Gastro Med Res. 4(2). GMR.000584. 2020.

DOI: 10.31031/GMR.2020.04.000584

Copyright@ Nam Nguyen, This article is distributed under the terms of the Creative Commons Attribution 4.0 International License, which permits unrestricted use and redistribution provided that the original author and source are credited.

\author{
Marie Ooi ${ }^{1}$, Tuan A Duong ${ }^{1}$ and Nam Q Nguyen ${ }^{1,2 *}$ \\ ${ }^{1}$ Department of Gastroenterology and Hepatology, Australia \\ ${ }^{2}$ Discipline of Medicine, Australia
}

\begin{abstract}
Food bolus obstruction (FBO) is a common presentation to Emergency Department. Majority of patients are elderly, and most have underlying esophageal pathologies. Eosinophilic esophagitis (EoE) has become a leading cause of food impaction in young adults. Recurrent FBO occurs in approximately $20 \%$ due to persistent underlying esophageal pathologies. Endoscopy remains the preferred method of food bolus extraction and treatment of the underlying esophageal pathologies. This review article aims to provide an update on the endoscopic management of FBO.
\end{abstract}

\section{Introduction}

Esophageal foreign body and food bolus obstruction (FBO) are common presentations to the emergency department and are usually managed by gastroenterologists. Generally, foreign body is defined as non-food product and its ingestion may be accidental which is commonly seen in children because of accidental swallowing or intentional which is more common in psychiatric patients and prisoners. On the other hand, food bolus obstruction is defined as esophageal obstruction due to unintentional ingestion of food products. Majority of FBO occur in the elderly population and men are more commonly affected than women [1]. Eosinophilic esophagitis (EoE) has become a leading cause of food impaction in young adults. The annual incidence of food bolus obstruction is estimated to be 13 to 25 in 100,000 [1,2].

\section{Risk factors for FBO}

There are certain "high risk groups" such as edentulous and intoxicated patients that have a higher tendency to FBO [1]. Majority of acute FBO is associated with underlying benign structural esophageal pathology such as peptic stricture, eosinophilic esophagitis (EoE), surgical anastomosis Schatzki ring or diverticula, (Figure 1) [3,4]. The most common site for food bolus obstruction is at the distal oesophagus [1]. Peptic stricture is reported as the most common cause of FBO, although there is also a growing recognition that the prevalence of eosinophilic esophagitis (EoE), an immune-mediated inflammatory disorder of the esophagus is on the rise over the past two decades, with more than a third of cases presented with FBO [3]. Interestingly, esophageal cancer (Figure 1) is an infrequent cause of food bolus obstruction in the Western population ( $2 \%)$, however, it is a common cause in China [2,5]. This may be related to different dietary intake and eating habits. In Asian countries such as in China, fish bone appears to be the most common cause of FBO, whereas the most common cause of FB in the Western countries is boneless meat $[4,6]$.

\section{Clinical assessment}

All patients who present with acute FBO should be clinically assessed. On arrival to emergency department patients' stability, airway patency and signs of aspiration pneumonia or esophageal perforation should be ascertained [4]. In contrast to true foreign body ingestions, FBO are almost always symptomatic as a result of partial or complete obstruction [4]. Patients can present with a wide range of symptoms, including dysphagia, odynophagia, a choking sensation, chest pain, coughing or wheezing. Hypersalivation or inability to swallow saliva is a sign of high-grade esophageal obstruction. Details on the time, type of 
food ingested, previous history or endoscopic findings of FBO and significant medical co-morbidities are important information to obtain [1-4]. There is minimal role for radiologic investigations in the setting of FBO. Chest X-ray is often not useful to identify very early signs of aspiration pneumonia and most boneless food boluses are radiolucent on chest x-ray. A barium contrast study is not recommended due to the potential risk of aspiration and a computed tomography (CT) scan is rarely indicated unless there is clinical suspicion of esophageal perforation [4].

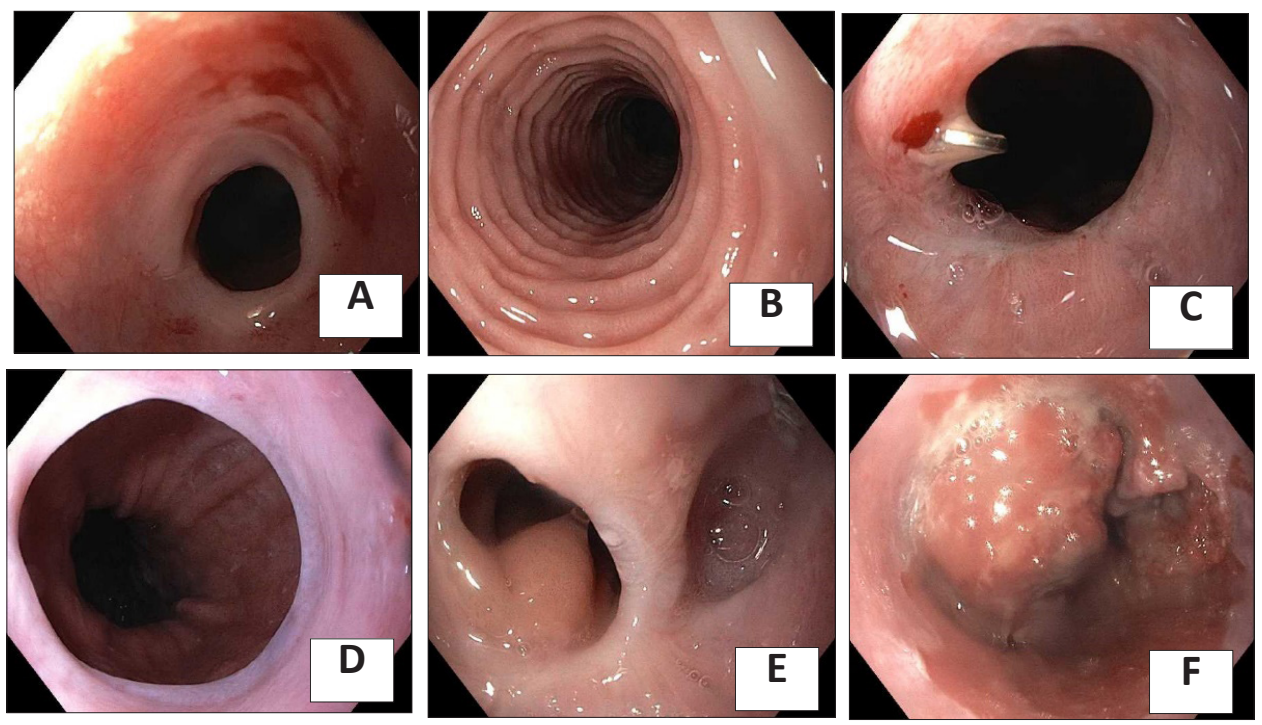

Figure 1:

(A)Peptic stricture.

(B) EoE.

(C) Anastomotic stricture.

(D) Schatzki's ring.

(E) Esophageal diverticulum.

(F) Malignant stricture.

\section{Management of FBO}

Most food boluses (FB) pass spontaneously into the stomach without requiring any endoscopic intervention. Approximately 1 in 5 cases still require intervention to remove food bolus obstruction (FBO) [6-9].

Non-endoscopic modalities: A trial of non-endoscopic modalities such as smooth muscle relaxants and carbonated beverages have been frequently used in the emergency department before proceeding to endoscopic intervention [4]. Examples of smooth muscle relaxants used are intravenous glucagon and hyoscine butyl bromide [4]. Carbonated beverages such as "Coke" has been tried based on the theory that gas release induces distension of the esophageal lumen to dislodge the food into the stomach [4]. However, the efficacy and success rates with the use of such agents have been variable and have been shown to be less successful in the setting of a high grade FBO or an underlying fixed luminal stenosis [4]. There are also reports on serious adverse events with the use of these agents. In addition, certain agent such as papain, a proteolytic enzyme was associated with electrolyte imbalance, mucosal erosions and esophageal perforation and is no longer recommended [4]. Hence, the safety of these various nonendoscopic treatment remains questionable [4].
Endoscopic modalities: Endoscopic removal of food bolus still remains the procedure of choice with a reported success rate of $>95 \%$ and minimal complications [7-10]. Patients with food bolus impaction that cannot manage their own secretion (i.e. complete obstruction) should have endoscopy urgently. Major guidelines recommend endoscopy to be performed within 24 hours of ingestion given a delay will decrease the chances of a successful removal of food bolus (FB) $[4,7,10]$.

There are currently a variety of endoscopic retrieval devices available, including net retrievers, polypectomy snares, dormia baskets, grasping forceps and tripod graspers [4,7,10-14]. The choice of endoscopic device(s) depends on device availability, type and size of food bolus, location of FBO within the esophagus and the preference of the endoscopists [4]. However, endoscopic removal of FB can be challenging, due to a limited working space within the esophagus and a restricted endoscopic view of the FB $[5,6]$. Endoscopic methods of FB removal involve either the extraction (pull) maneuver or the advancement (push) maneuver [4,7]. Most soft non-impacted FB can be pushed by gentle pressure or by air insufflation. However, for patients who failed the push maneuver or has bony food impaction with sharp edges, pull maneuver is recommended [4]. Food bolus can be removed either in an en bloc (Figure 2) or in a piecemeal fashion [4]. 

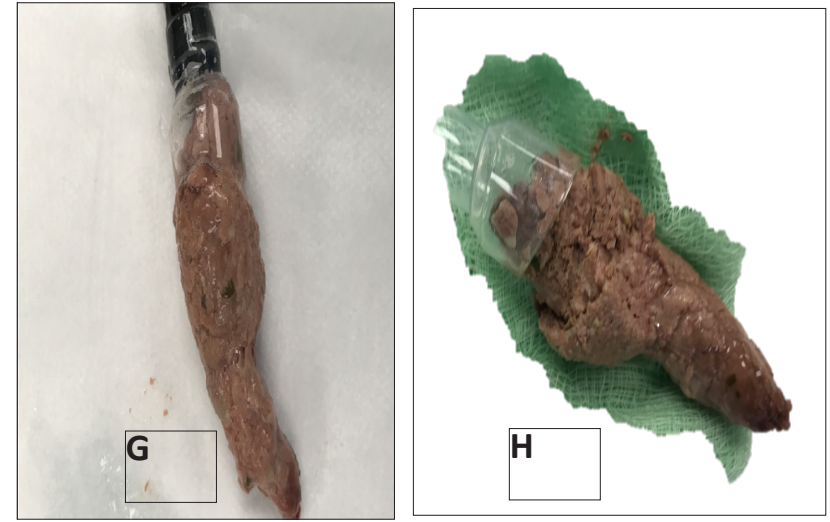

Figure 2: En-bloc removal of food bolus obstruction using the cap.

Conventional endoscopic devices tend to remove FB after fragmentation in a piecemeal fashion and may result in an incomplete removal of FB [4]. Recently, cap-assisted endoscopy has been increasingly used in clinical practice [15]. Cap-assisted technique has been shown to improve endoscopic visual field and working space within the gastrointestinal lumen such as in endoscopic mucosal resection (EMR), submucosal dissection (ESD), therapeutic third space endoscopy, endoscopic hemostasis, foreign body retrieval and during screening colonoscopy [15]. Cap-assisted technique has also been successfully used in both foreign body and food bolus retrieval [5,6,16-18]. Zhang et al. [16] demonstrated the use of a large- caliber, soft and transparent cap, not only improved endoscopic visualization but also improve the effectiveness of impacted chicken or fish bones and was associated with a shorter procedure time. Ooi et al [6] also reported on the effectiveness of the cap-assisted technique in boneless food bolus retrieval.
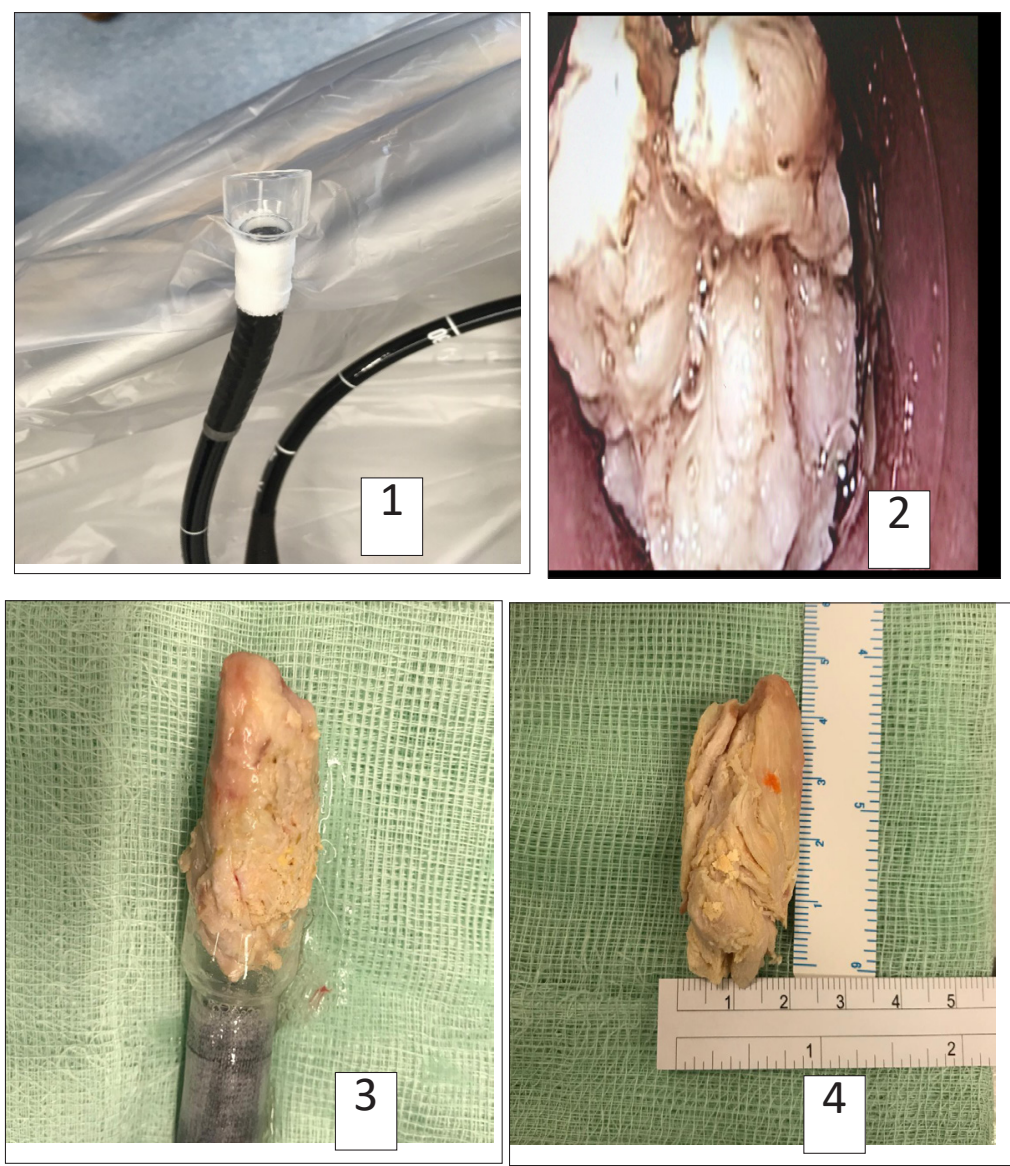

Figure 3:

Step 1: Cap attached to the tip of the endoscope.

Step 2: Wall suction is applied to disengage the food bolus from the esophageal wall into the cap.

Step 3: Endoscope together with the food bolus is withdrawn out of the oral cavity, Step 4: An en bloc removal of food bolus. 
The types of cap available in clinical practice are straight or oblique, hard or soft [15]. Hard caps are reusable after sterilization whereas soft caps are disposable [15]. Ooi et al. [6] explained the steps using the cap assisted technique in retrieval of food bolus obstruction (Figure 3).

Step 1: A disposable soft oblique cap (D-206-04; Olympus, Japan) with an outer diameter of $18.1 \mathrm{~mm}$ is mounted onto the tip of a standard endoscope,

Step 2: Wall suction is applied to engage food bolus into the cap and dislodge it from the surrounding esophageal wall.

Step 3: The endoscope with the food bolus attached to the tip of the scope is gently withdrawn out of the oral cavity using constant suction and a complete en-bloc removal of food bolus.

\section{Management after food bolus extraction}

Once food bolus has been removed, any underlying esophageal stenosis needs to be addressed to reduce the risk of recurrent food bolus obstruction. It is recommended that esophageal biopsy should be taken for patients with esophageal food impaction due to reported increased incidence of EoE. In addition, patients with clinical suspicion of EoE should be commenced on proton pump inhibitor. It is estimated that recurrence rate of FBO to be $10-20 \%$ due to persistent underlying esophageal pathology $[14,19]$. One of the preventative strategies to reduce the rate of recurrent FBO is endoscopic dilation of any underlying esophageal stricture [4]. However, ideal timing of esophageal dilation is largely unknown and current data on the safety of esophageal dilation in the same endoscopic session immediately after removal of food bolus are very limited [20]. The decision on the timing of endoscopic dilation is currently based on the discretion of endoscopists [20].

Early reports of esophageal dilation especially in the setting of EoE raised concerns of mucosal tear, bleeding (Figure 4) or even perforation due to the fragility of the inflamed esophageal mucosa [21-24]. However, recent systemic and meta-analysis suggested that dilation in the setting of EoE is safe and effective [25-29]. Dilatation in EoE is effective in 95\% of patients and with less than $1 \%$ complication rate. Perforation, which is the most feared complication from esophageal dilation, occurs in $0.3 \%$ of patients. In addition, Ooi et al. [30-35] showed that same-session endoscopic dilatation of benign esophageal after the removal food bolus obstruction appeared safe and effective. If dilatation is to be done, it is important to obtain consent form prior to the procedure. Patients should be explained of chest pain $2^{\text {nd }}$ to mucosal tear from the dilatation, which usually managed with re-assurance, simple analgesia and rarely with opioid analgesia [36]. The technique of esophageal dilation is reviewed elsewhere [36]. Briefly, the objective is to have the esophagus dilated to a minimum diameter of $16-18 \mathrm{~mm}$, which can be achieved with single or multiple sessions of 3-4 weeks apart. It is important to start with small-diameter dilators and gradually increase in dilator size. There are different techniques include through the scope balloon dilatation, Savary bougies and Maloney bougies.

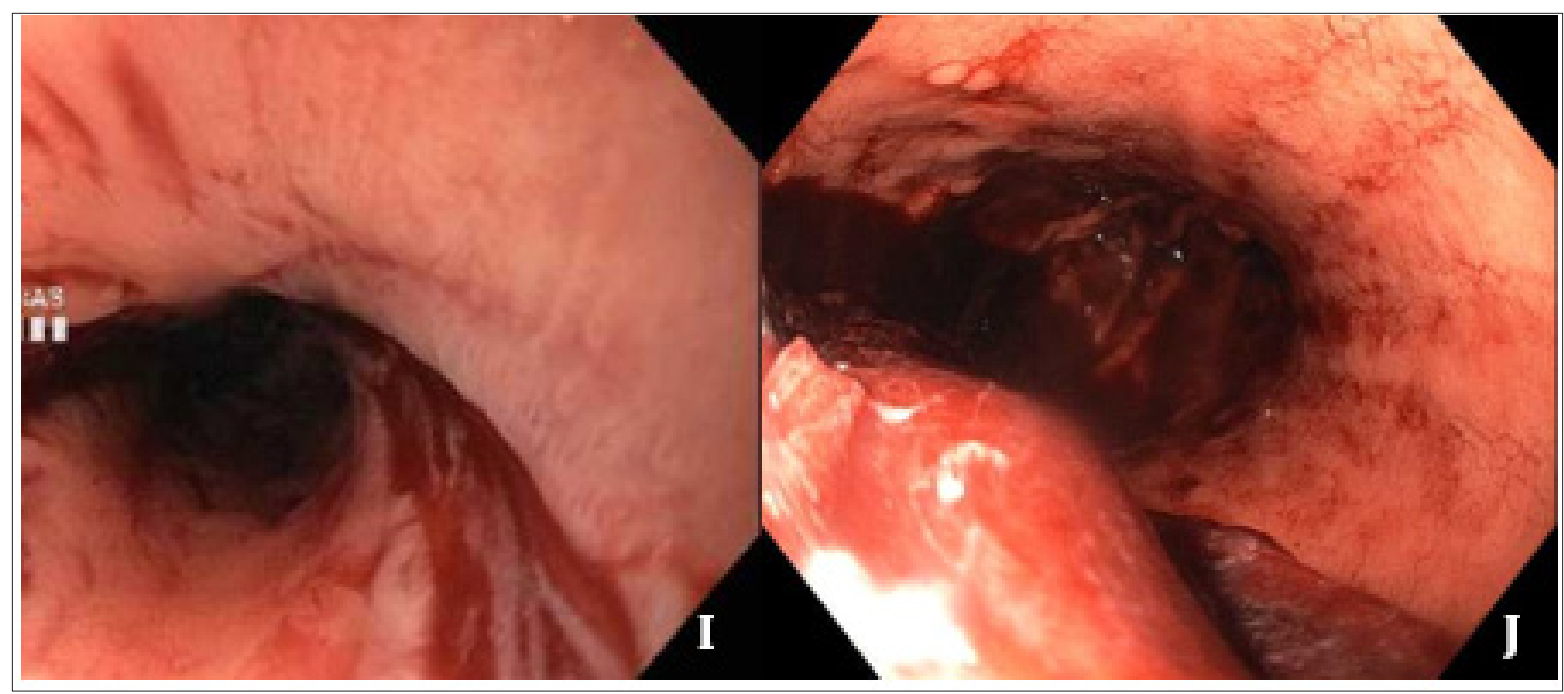

Figure 4: Endoscopic image of mucosal tear and bleeding after oesophageal dilation.

\section{Conclusion}

Endoscopic management remains the most effective method in removal of food bolus obstruction as well as treatment of any underlying structural esophageal pathology. Traditionally, endoscopic devices such as net retrievers, snares, baskets, biopsy forceps or tripod graspers have been used to remove food bolus, however cap-assisted technique appears promising and may potentially change current clinical practice. The recurrence rate of
FBO is approximately $20 \%$ and early management of underlying esophageal pathology including endoscopic dilation is crucial to reduce the risk of recurrent FBO. However, further large randomized studies are warranted.

\section{References}

1. Longstreth GF, Longstreth KJ, Yao JF (2001) Esophageal food impaction: Epidemiology and therapy. A retrospective, observational study. Gastrointest Endosc 53(2): 193-198. 
2. Gretasdotti HM, Jonasson JG, Bjornsson ES (2015) Etiology and management of esophageal food impaction: A population-based study. Scand J Gastroenterol 50(5): 513-518.

3. Mahesh VN, Holloway RH, Nguyen NQ (2013) Changing epidemiology of food bolus impaction: is eosinophilic esophagitis to blame? J Gastroenterol Hepatol 28(6): 963-966.

4. Ikenberry SO, Jue TL, Anderson MA, Appalaneni V, Banerjee S, et al. (2011) Management of ingested foreign bodies and food impactions. Gastrointest Endosc 73(6): 1085-1091.

5. Zhang S, Cui Y, Gong X, Gu F, Chen M, et al. (2010) Endoscopic management of foreign bodies in the upper gastrointestinal tract in South China: a retrospective study of 561 cases. Dig Dis Sci 55(5): 1305-1312.

6. Ooi M, Young EJ, Nguyen NQ (2018) Effectiveness of a cap-assisted device in the endoscopic removal of food bolus obstruction from the esophagus. Gastrointest Endosc 87(5):198-203.

7. Nelson DB, Bosco JJ, Curtis WD, Faigel DO, Kelsey PB, et al. (1999) ASGE technology status evaluation report. Endoscopic retrieval devices. American Society for Gastrointestinal Endoscopy. Gastrointest Endosc 50(6): 932-934.

8. Magalhaes-Costa P, Carvalho L, Rodrigues JP, Túlio MA, Marques S et al. (2016) Endoscopic management of Foreign bodies in the upper gastrointestinal tract: An evidence-based review article. GE Port J Gastroenterol 23(3): 142-152.

9. Sugawa C, Ono H, Taleb M, Lin SC, Liang CH, Kuo YH, et al. (2014) Endoscopic management of foreign bodies in the upper gastrointestinal tract: A review. World J Gastrointest Endosc 6: 475-481.

10. Birk M, Bauerfeind P, Deprez PH, Häfner M, Hartmann D, et al. (2016) Removal of foreign bodies in the upper gastrointestinal tract in adults: European Society of gastrointestinal Endoscopy (ESGE) Clinical guideline. Endoscopy 48(5): 489-496.

11. Ko HH, Enns R, Deprez PH, Häfner M, Hartmann D, et al. (2008) Review of food bolus management. Can J Gastroenterol 22: 805-808.

12. Faigel DO, Stotland BR, Kochman ML, Hoops T, Judge T, et al. (1997) Device choice and experience level in endoscopic foreign object retrieval: An in vivo study. Gastrointest Endosc 45(6): 490-492.

13. Smith MT, Wong RK (2006) Esophageal foreign bodies: Types and techniques for removal. Curr Treat Options Gastroenterol 9(1): 75-84.

14. Vicari JJ, Johanson JF, Frakes JT (2001) Outcomes of acute esophageal food impaction: Success of the push technique. Gastrointest Endosc 53(2): 178-181.

15. Sumiyama K, Rajan E (2006) Endoscopic caps. Tech Gastrointest Endoscopy 8: 28-32.

16. Zhang S, Wang J, Wang J, Zhong B, Chen M, et al. (2013) Transparent cap-assisted endoscopic management of foreign bodies in the upper esophagus: a randomized, controlled trial. J Gastroenterol Hepatol 28(8): 1339-1342.

17. Patel NC, Fry LC, Monkemuller KE (2003) Modified suction cap technique for endoscopic management of esophageal food impaction. Endoscopy 35(6): 548.

18. Lee JS, Chun HJ, Lee JM, Hwang YJ, Kim SH, et al. (2013) Salvage technique for endoscopic removal of a sharp fish bone impacted in the esophagus using a transparent cap and detachable snares. Korean J Gastroenterol 61(4): 215-218.

19. Prasad GA, Reddy JG, Boyd-Enders FT, Schmoll JA, Lewis JT, et al. (2008) Predictors of recurrent esophageal food impaction: A case-control study.
J Clin Gastroenterol 42(7): 771-775.

20. Weinstock LB, Shatz BA, Thyssen SE (1999) Esophageal food bolus obstruction: evaluation of extraction and modified push techniques in 75 cases. Endoscopy 31(6): 421-425.

21. Cohen MS, Kaufman AB, Palazzo JP, Nevin D, Dimarino AJ Jr, et al. (2007) An audit of endoscopic complications in adult eosinophilic esophagitis. Clin Gastroenterol Hepatol 5(10): 1149-1153.

22. Furuta GT, Liacouras CA, Collins MH, Gupta SK, Justinich C, et al. (2007) Eosinophilic esophagitis in children and adults: a systematic review and consensus recommendations for diagnosis and treatment. Gastroenterology 133(4): 1342-1363.

23. Kaplan M, Mutlu EA, Jakate S, Bruninga K, Losurdo J, et al. (2003) Endoscopy in eosinophilic esophagitis: "feline" esophagus and perforation risk. Clin Gastroenterol Hepatol 1(6): 433-437.

24. Hirano I (2010) Dilation in eosinophilic esophagitis: To do or not to do? Gastrointest Endosc 71(4): 713-714.

25. Webb WA (1995) Management of foreign bodies of the upper gastrointestinal tract: update. Gastrointest Endosc 41(1): 39-51.

26. Richter JE (2017) Esophageal dilation for eosinophilic esophagitis: it's safe! Why aren't we doing more dilatation? Gastrointest Endosc 86(4): 592-594.

27. Dougherty M, Runge TM, Eluri S, Dellon ES (2017) Esophageal dilation with either bougie or balloon technique as a treatment for eosinophilic esophagitis: A systemic review and meta-analysis. Gastrointest Endosc 86(4): 581-591.

28. Moawad FJ, Molina-Infante J, Lucendo AJ, Cantrell SE, Tmanova L, et al. (2017) Systematic review with meta-analysis: endoscopic dilation is highly effective and safe in children and adults with eosinophilic esophagitis. Aliment Pharmacol Ther 46(2): 96-105.

29. Moole H, Jacob K, Duvvuri A, Moole V, Dharmapuri S, et al. (2017) Role of endoscopic esophageal dilation in managing eosinophilic esophagitis: A systematic review and meta-analysis. Medicine 96(14): e5877.

30. Alexander JA (2014) Esophageal dilation in eosinophilic esophagitis. Technique in gastrointestinal endoscopy 16(1): 26-31.

31. Hiremath G, Vaezi MF, Gupta SK, Acra S, Dellon ES (2018) Management of esophageal food impaction varies among gastroenterologists and affects identification of eosinophilic esophagitis. Dig Dis Sci 63(6): 1428-1437.

32. Kramer RE, Lerner DG, Lin T, Manfredi M, Shah M, et al. (2015) Management of ingested foreign bodies in children: a clinical report of the NASPGHAN endoscopy committee. J Pediatr Gastroenterol Nutr 60(4): 562-574

33. Evans DC, Wojda TR, Jones CD (2015) Intentional ingestions of foreign objects among prisoners: A review. World Journal of Gastrointestinal Endoscopy 7(3): 162-168.

34. Palese C, Al-Kawas FH (2012) Repeated intentional foreign body ingestion: The importance of multidisciplinary approach. Gastroenterol Hepatol 8(7): 485-486.

35. Ooi M (2018) The safety and treatment outcome of same-session endoscopic dilatation (SSED) of benign esophageal Stricture after removal of food bolus obstruction: A Prospective Longitudinal StudyAbstracts submitted to DDW 2019.

36. Mahesh VK, Holloway RH, Nguyen NQ (2013) Changing epidemiology of food bolus impaction: is eosinophilic esophagitis to blame? Gastroenterol Hepatol 28(6): 963-966. 